\title{
Automation and Safety Measurements At Railroad Intersection using Iot
}

\author{
P. V. Rama Raju, G. Naga Raju,J. Ravi Teja, G. Hemanth Prakash, J. Mouni Priyanka
}

\begin{abstract}
The target of this undertaking is to robotize railroad passages without individuals and to check rail course scenes. At present level railroad sections are worked physically by a guardian. The watchman gets the data about the area of train from a close to station. This human mediation can be stayed away from through automating the structure. In a bit of the time the train is late a possible result of some reason the areas stay shut for whole game plan and causing thick traffic close to the entries. This undertaking is made with $R F$ transmitter and recipient, RFID Reader, Arduino, Raspberry pie, nodemcu, blynk application, camera, ring, LCD show up, IR Module, Servo Motors and play back module. In our proposed model the $R F$ transmitter and RFID Reader are embarked to plan. Totally when the train arrives the RFID Reader takes a gander at the tag, by then the RF Transmitter transmits the data about the section of train through radio wire and the $R F$ Receiver set at the railroad intersection point gets the data about the zone of train and offers data to the Arduino. Arduino will control the servo engines to open and close the railroad portals. The LCD show additionally put at the blending to caution the pilgrims by displaying parcel of train from railroad crossing. The voice module other than set to caution the voyagers. On the off chance that the voyagers trying to cross the entry even after the voice sign about the landing of train then they will thusly get the fine with the assistance of camera and Raspberry pie. The touch plates on the track what's more gives data about the locale of people on the track.
\end{abstract}

Keywords:automation, obstacle detection, receiver and transmitter

\section{INTRODUCTION}

At present transportation perceive an essential movement in each human life. There are different methodologies for transportations like Roadways, Airways and Waterways. The Railway structure is the most routinely utilized transportation in India and a holy person among the best transportations. Notwithstanding, there are more occasions because of human nonappearance of respect of shutting railroad sections.

The essential test looked by the Indian Railways is the making fiasco rate at the level crosses. When we experience the constantly papers we go over different railroad episodes happening at paid special mind to rail line crossings. This is ordinarily a quick delayed consequence of the

Revised Manuscript Received on April 12, 2019.

P. V. Rama Raju, Professor \& HOD, Department of ECE, SRKR Engineering college(A), Bhimavaram, A.P, India.

G. Naga Raju, Asst. Professor, Department of ECE, SRKR Engineering college(A), Bhimavaram, A.P, India.

J. Ravi Teja, B.E Students, Department of ECE, SRKR Engineering college(A), Bhimavaram, A.P, India.

G. HemanthPrakash, B.E Students, Department of ECE, SRKR Engineering college(A), Bhimavaram, A.P, India.

J. MouniPriyanka,B.E Students, Department of ECE, SRKR Engineering college(A), Bhimavaram, A.P, India.

nonappearance of alert in manual errands or nonattendance of experts.

In the present situation there are two sorts of railroad gatherings:

\section{Manned \\ 2.Unmanned}

Different catastrophes occur because of the manual endeavor of the whole structure.

The present structure sets the manual entry task by the watchmen subject to the sign got from the power room. The human slips, for instance, delay in enlightening the watchman about the area of the train, delay in the passage movement by the guard, check stuck in the level cross, etc prompts the expanding rate of disasters at the level cross. Along these lines the railroad passage computerization structure intends to manage two things. It diminishes the full scale time made for the segment move at the level cross and in addition guarantees the achievement of the voyagers at the level cross during when the train passes. The decrease in the practical human intercession during the entryway activity thusly reduces the fiasco and episodes at the level cross. Since the entryway errands are electronic subject to the sensors, the perfect open area for which the entryway is shut is less. The paper as necessities be plans to develop a modified railroad section control structure which is affirmed and checked than the present manual frameworks. So to decrease the issue of this railroad mishaps we mechanized the opening and shutting of rail course portals.

Despite this the train driver doesn't know any data about the vicinity of people with the target that we are setting contact plates on the track to see individuals.

The standard inspiration of doing this undertaking is the dependable railroad episode in Amritsar. To diminish such kind of railroad catastrophes we are setting contact plates to see people on the track and offers a comprehension to the driver.

The voyagers will try to cross the gateway even after the sign of getting in contact of train so we are putting camera and on the off chance that anybody will endeavoring to cross section after sign they will henceforth get fine with the affirmation of their vehicle plate number utilizing camera. With the target that nobody should cross after sign.. 


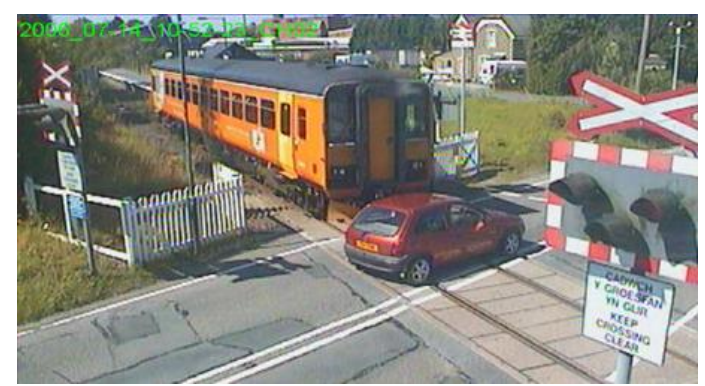

Fig 1:Real time example

Necessities of existing structure:

- Chances of human destruction up

- Time eating up

- A store of human asset is required

The remainder of the paper is made as scans for after. Section 2 delineates the outline of past papers. Section 3 and 4 delineates equipment and programming contraptions utilized in our structure energetically. Part 4 delineates the structure plan and stream format. Section5 diagrams test results and section6 portrays the end and future addition.

\section{RELATED WORK:}

IR based balanced railroad control [1]. Interfacing with sensors put underground are less impacted by normal changes and sees the course of improvement of vehicles [2]. Jeong [3] portrayed the railroad auto control framework utilizing OGSi and JESS. In [4], a positive presentation about the present railroad improvement is shown. It slows down the loads of physically actuated railroad signals and the railroad urges at the level cross. The train pioneers goes about as the guaranteed piece in the train mechanization structure. Ultra-Wideband Radar System for Detection at Railway Crossings. Because of constrainments of IR framework, the radar structure is proposed at the union point. GPS and GPRS Based Detection System[5], Many structures were proposed subject to sensor at any rate they were gainful up to some expand allegorically. VideoAnalysis Based Railway Road Safety System, in this structure, camcorder is exhibited at the mix. The fundamental bundling work is of picture engineering based railroad crossing observation. It will send the photos of the intermingling point to the train drivers. The peril way is depicted in this framework. Introduction to raspberry pi and about stick configuration[8]. Stick structure and presentation about Arduino[9].

\section{HARDWARE COMPONENTS:}

- Arduino

- $\quad$ RFID Reader and names

- RF Transmitter

- RF Receiver

- LCD show up

- $\quad$ Servo engines

- Raspberry pie

- Camera module

- $\quad$ Play back module

\section{SOFTWARE TOOLS:}

- Arduino IDE

- Python

\section{SYSTEM ARCHITECTURE:}

In India the most striking rate at which a train moves is $91.82 \mathrm{~km} / \mathrm{hr}$ and the base speed of a voyager/things train is $59 \mathrm{~km} / \mathrm{hr}$. In this manner the ideal pack at which the sensors could be put to see the territory of the train is $5 \mathrm{~km}$ from the level cross and the takeoff of the train is $1 \mathrm{~km}$ and thusly the entryway won't be shut for more than 8 minutes [6].

The square blueprint of proposed is as appeared by the going with.
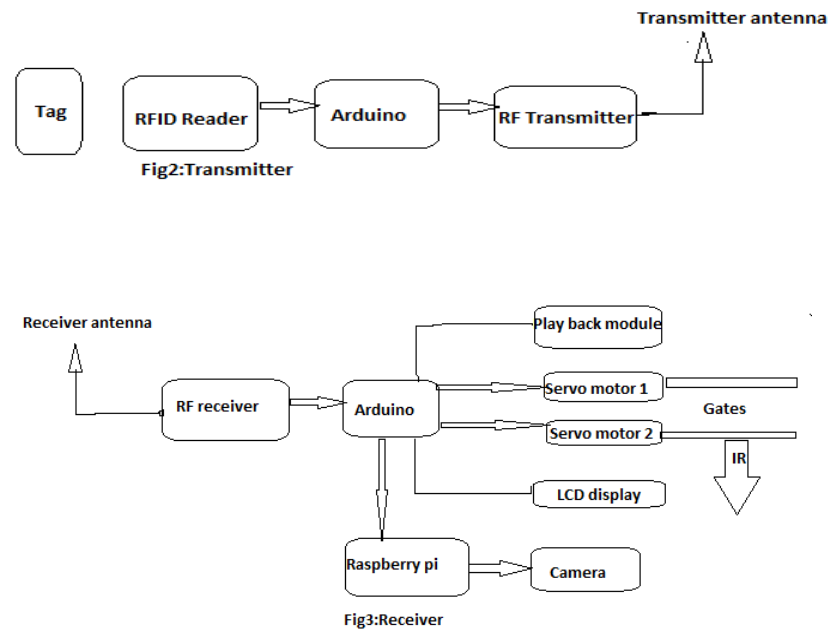

\subsection{Transmitter:}

In this proposed structure the RFID peruser on the train sees the tag and data about the part of train is transmitted utilizing RF transmitter.

\subsection{Receiver:}

By then the RF gatherer gets the data about the district of train and gives this data to the Arduino. By then Arduino controls play back module, LCD show and servo engines.

\subsection{Safety measures before shutting the area:}

Quickly the red LED will attempt to satisfy the voyagers to stop cross the railroad crossing. The voice sign is what's increasingly given about the status of the train utilizing play back module. The division of train from the social affair is other than showed up on the LCD show up and the ringer activates[7].

By then continuously servo engines turn over shutting the portal. In the event that no vehicle found underneath the entryway it will closes totally. As the general open won't quit paying little mind to for such boundless signs about touching base of train and they are up 'til now grasped to cross the section. To oust these conditions we are setting IR module underneath the zone. On the off chance that any vehicle saw when entryway shutting, by then servo engines stop and the camera module begins and snap the picture of vehicle number and that pic will be send to them and they need to pay fine. This sign is in like way given at the railroad crossing with the target that they won't cross after sign about the region of train. The status of the opening and 
shutting of entries is in like way given to the driver as notice. The trek of train in like way observed by RFID peruser and the servo engines opens the segment.

Beginning late the yearly Dussehra party finished in a calamity in Amritsar, Punjab in setting on railroad misfortune as authoritative lack of caution and open nonattendance of thought towards advancement took in any event 60 lives and crippled many. A train slipped individuals seeing the celebrations. They were on the tracks neglectful of the pushing toward train. So to imagine such railroad disasters we are putting contact sensors on the track and if individual present on the track a notice is given to the driver to make basic move.

This model in like way gives the status about the railroad crossing with driver. Along these lines we utilized blynk application and nodemcu to pass on the data and status of the railroad ways to deal with the driver and blynk application gives watches.

\subsection{Flow chart:}

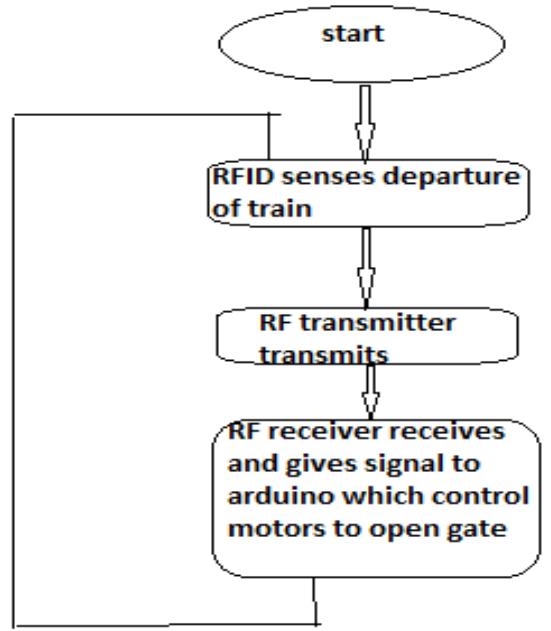

Fig:4 Flow chart to open gate

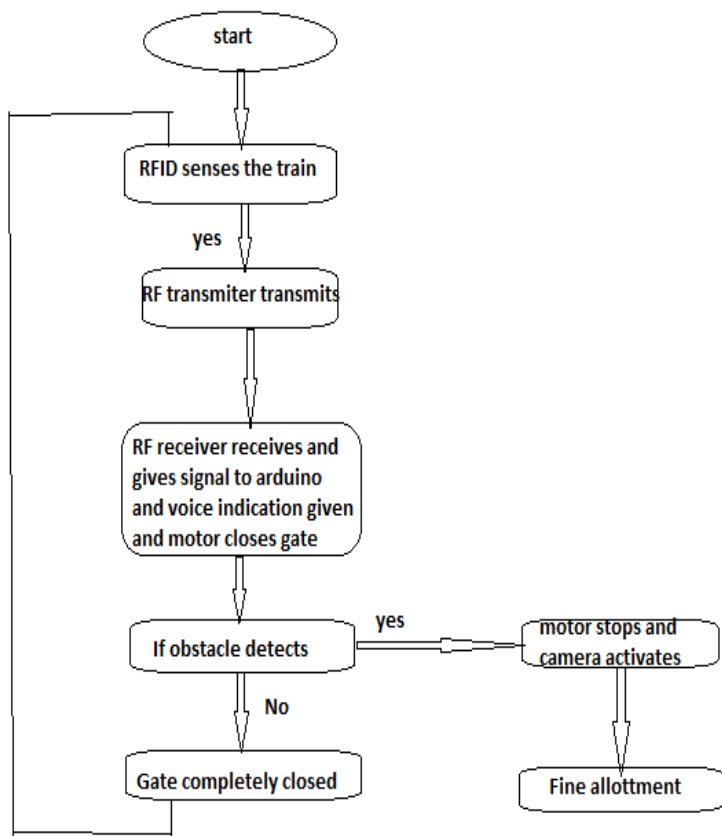

Fig:5 Flow chart for gate closing

\section{RESULTS:}

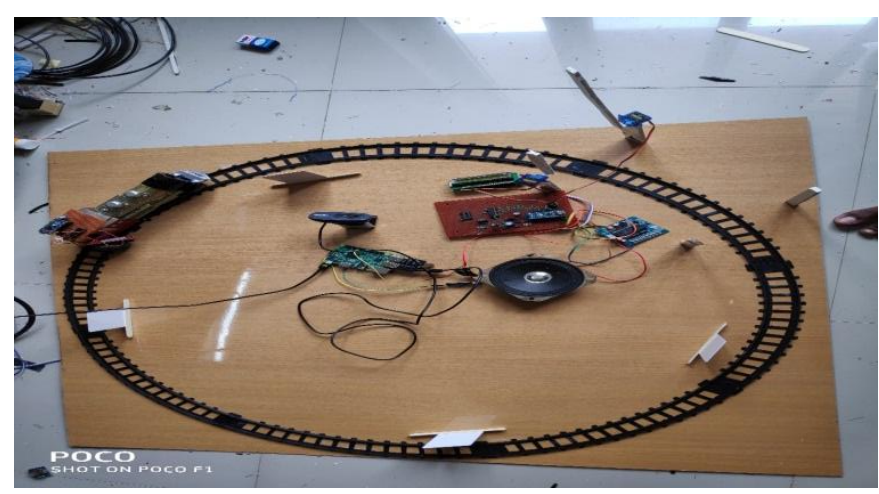

Fig6: Figure of kit

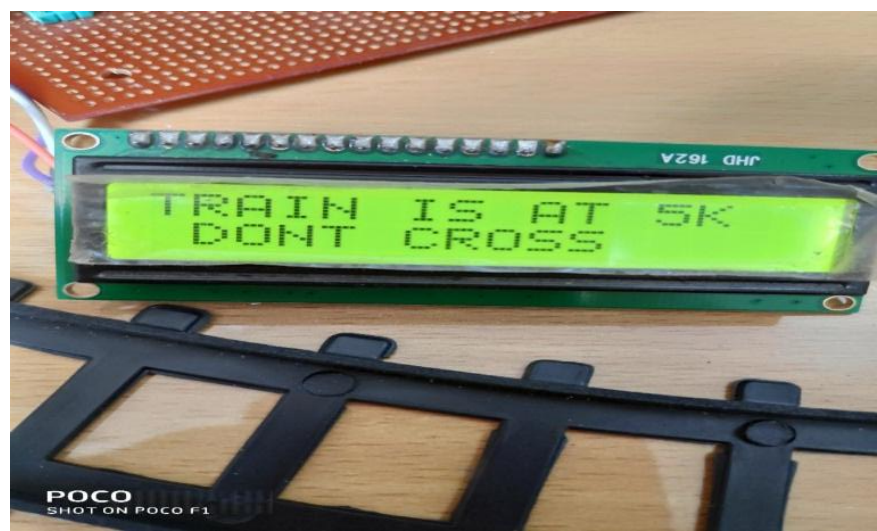

Fig7: When train is at $5 \mathrm{~km}$ 


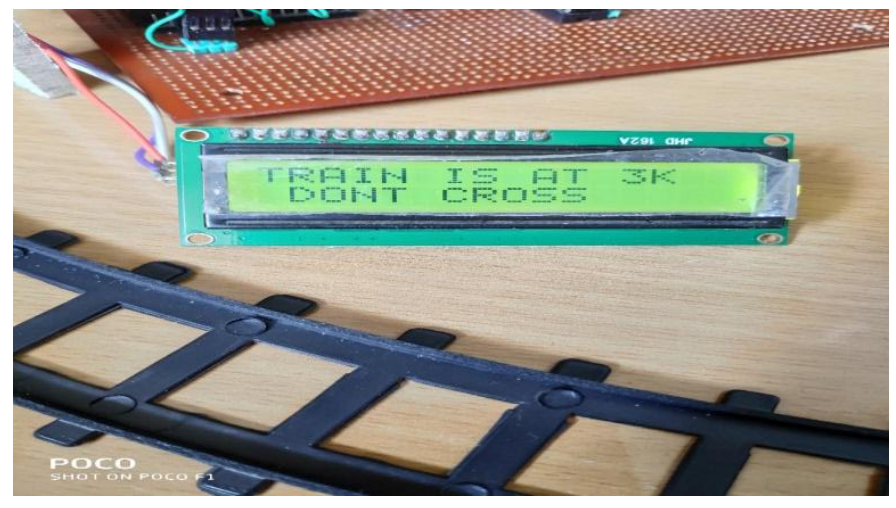

Regarding fine payment

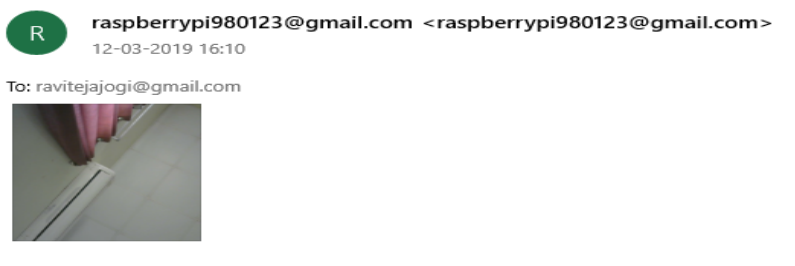

You crossed the gate after announcement you have to pay fine, See the attached picture.

Fig11:Email received if a person crosses the gate after indication

\section{CONCLUSION AND FUTURE SCOPE:}

Adjusted railroad gateway control structure depends on diminishing human obligation with respect to shutting and opening the railroad entrance which permits and keeps vehicles and people from affiliation railroad tracks. The railroad area is a clarification behind express passings and

Fig8: When train is at $3 \mathrm{~km}$

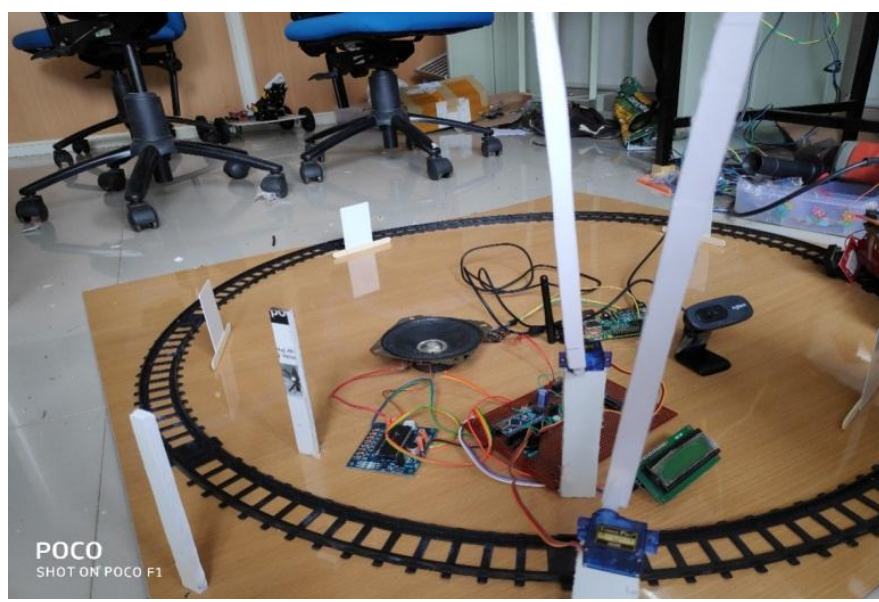

Fig9: The gate is in open condition

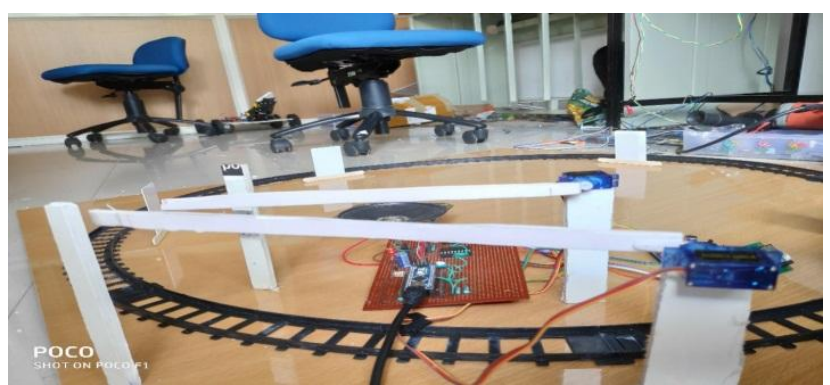

Fig10: The gate is in closed condition accidents.Consequently, motorizing the part can esteem a ring of security to controlling the sections. Human may submit insufficiencies or bungles so robotization of railroad entryways will reduce the odds of gateway disappointments. Robotization of the end and opening of the railroad entry utilizing this proposed model decreases the difficulties to an interminably major degree. The check introduction structure perceived declines the scenes which are routinely caused when the railroad line encounters the timberland. A colossal piece of the occasions consistently principal hardship has been caused when creatures cross the tracks.

In future we other than improve this framework to see the inadequacies in the track and offers data to the driver about the area of track issue utilizing ground affiliation. Weight sensor can be accomplished the present work to decrease little goofs. We moreover improve to give an approach to manage regulate ambulances on the off chance that they accomplice at the period of shutting the entryway and it will relies upon the time and conceivable precisely when there is pleasing opportunity to cross the rescue vehicle before the train comes. As a future level of work, our framework can be perceived constantly by fixing the present controls utilizing new upgrades.

\section{REFERENCES}

1. International Journal of Advanced Research in Computer Engineering \& Technology (IJARCET) Volume 4 Issue 2, February 2015

2. Xishi Wang, Ning Bin, and Cheng Yinhang, "A new microprocessor based approach to an automatic control system.", International Symposium on Industrial Electronics, pp. 842-843, 1992.

3. Jeong Y., Choon-Sung Nam, Hee-Jin Jeong, and Dong Shin, "Train Auto Control System based on OSGi", International Conference on Advanced Communication Technology, pp.276-279, 2008.

4. Atul Kumar Dewangan, Meenu Gupta, and Pratibha Patel, "Automation of Railway Gate Control Using Microcontroller, International Journal of Engineering Research \& Technology, pp.1-8, 2012.

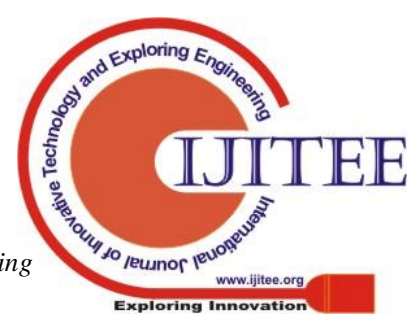


5. Y.Lei, H.Xiao, "Research on alarm system of railway crossing based on GPS and GPRS,"IEEE China 2011".

6. Pradeep Raj, "Increasing accidents in the unmanned level crossing of the railways", 2012.

7. Gunyoung Kim, Kyungwoo Kang, "Railway Gate Control System at Railroad-Highway Grade Crossing in Korea"

8. Introduction to raspberry pi and about pin configurationwww.raspberrypi.org

9. Introduction to Arduino and about pin configurationwww.arduino.cc

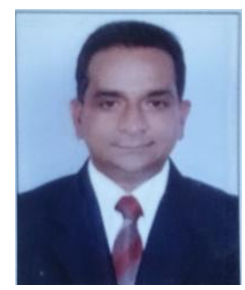

\section{ABOUT AUTHORS:}

\section{Dr.P.V.RamaRaju}

Presently working as a Professor and HOD of Department of Electronics and Communication Engineering, S.R.K.R. Engineering College, AP, India. His research interests include BiomedicalSignal Processing, Signal Processing, Image Processing, VLSI Design, Antennas and Microwave Anechoic Chambers Design. He is author of several research studies publishedin nationalandinternational journals and conferenceproceedings.

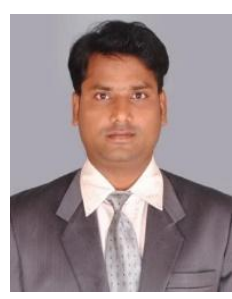

\section{G. Naga Raju}

Presently working as assistant professor in Dept. of ECE, S.R.K.R. Engineering College, Bhimavaram, AP, India. He received B.Tech degree from S.R.K.R Engineering College, Bhimavaram in 2002, and M.Tech degree in Computer electronics specialization from Govt. College of Engg., Pune University in 2004. His current research interests include Image processing, digital security systems, Signal processing, Biomedical Signalprocessing, and VLSI Design.

\section{J. Ravi Teja}

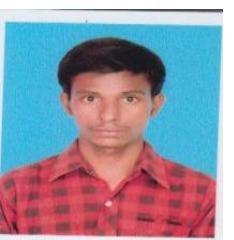

Presently pursuing Bachelor of Engineering degree in Electronics \& Communication engineering at S.R.K.R. Engineering College, AP, India. Email: ravitejajogi@gmail.com

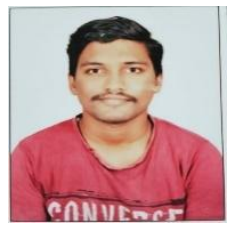

\section{G. Hemanthprakash}

Presently pursuing Bachelor of Engineering degree in Electronics \& Communicationengineering at S.R.K.R. Engineering College, AP, India.

Email:hemanthprakashgorli@gmail.com

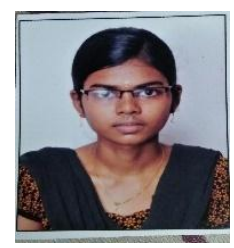

\section{J. MouniPriyanka}

Presently pursuing Bachelor of Engineering degree in Electronics \& Communication engineering at S.R.K.R. Engineering College, AP, India.

Email:priyankajangala1998@gmail.com 